DOI https://doi.org/10.36059/978-966-397-110-0/60-78

\title{
THE FORMATIVE ROLE OF THE CHINESE PHILOSOPHICAL AND ETHICAL IDEAS IN THE CULTURE OF THE EAST ASIAN REGION
}

\author{
Kudrya I. G.
}

\section{INTRODUCTION}

All East Asian states have a common cultural and civilizational basis for development. By cultural and civilizational basis, we understand the system of transcendental values that determine the most important aspects of the life of society and the state of East Asia.

The fundamental transcendental values of the countries of the Far East were formulated within the framework of the ancient Chinese civilization. Over the centuries, Chinese philosophical and ethical ideas have constantly influenced the consciousness of the nations of East Asia. Chinese civilization gave the cultures of the East Asian region not only philosophy, ethics, model of government, examples of art, he and hieroglyphic writing. The hieroglyph can be painted with a brush, a word or a battle sword. The hieroglyph reveals the degree of qualification and competence of a person.

At the same time, the connection with the Chinese civilization turned out to be so strong that it can be said that the Chinese ideological influence laid the civilizational foundations of the Far Eastern culture. Chinese ideas determined the general direction of thought in East Asia. Their influence on the consciousness of the Far Eastern peoples is related to the fact that they largely contained a transcendental component, essentially representing the system of coordinates of human existence, the structure of the ultimate bases of human experience and the picture of the world.

The main feature of the Chinese system of transcendental values was the understanding of being, through the universality of ethics and pragmatism. In the Chinese system of values, physical phenomena act as ethical functions.

Outside of these values, one cannot understand the culture and history of the Far East. Their influence on the culture of the East Asian states was all-encompassing: Buddhism and Taoism determined the self- 
perception of a person, his attitude to the world, Confucianism - the nature of relations in the family, society and the state. «... China in one significant respect shared a common world-view orientation to the Axial-age civilizations of the east Mediterranean sphere. Diverging from its Hinduist and Buddist counterparts, China developed a very strong thisworldly conception of 'salvation' which placed central emphasis on the social and political orders as the sites and foci of transcendental visions similar to those of ancient Greek and Hellenistic civilizations. It developed significant capacities for the 'rational' resolution of human or ethical dilemmas (that is, Confucianism and neo-Confucianism) in a fashion akin to those of ancient Greece and Rome.

This obviated the need for deistic objectivations and resolutions of existential-soteriological crises of the kind which came to define monotheistic civilizations as well as the other-worldly (non-deistic) oriented Hinduist and Buddist civilizations. In the antithetical mode, China also diverged from Greece and Rome in its mundane 'secular' orientation in the following ways: it more fully articulated the paradox of embodying a transcendental vision whilst resorting to a worldly conception of how to bridge these world-orders as result of acquiring an imperial form; it succeeded more forcefully than either Greek or Hellenistic civilizations in stressing the "proper performance of worldly duties and activities within the existing social frame-works ... as the ultimate criterion of the resolution of the tension between the transcendental and mundane order and of individual responsibility'; it had very tightly interwoven the realms of speculative and political life, as exemplified by the Confucian literati; and, finally, China's 'special conception of its resolution' of the tension between world renunciation and affirmation was decidedly marked by a 'strong semi-sanctification of the imperial order' that was absent in the (ancient) Mediterranean cases». ${ }^{1}$

\section{The formation of the transcendental foundations of Chinese civilization}

In general, Chinese civilization was characterized by the leitmotif of continuous improvement, through education, ethical upbringing, physical health, aesthetic pleasure and psychological comfort

${ }^{1}$ Mandalios J. Civilizational Complexes and Processes: Elias, Nelson and Eisenstadt. In Handbook of historical sociology / ed. by Gerard Delanty and Engin F. Isin. London; Thousand Oaks, Calif.: SAGE, 2003. P. 75. 
The scientific discussion between the Confucians, the Taoists and the Buddhists was constantly under way, each of these currents with detailed criticism of each other. There was a meeting of scientists of different perspectives on which the topical issues of that time were discussed. This turn stimulated the development of philosophy, science and technology in China. This method of attracting the views of various scientific schools and integrating them into a viable theory remains a central feature of Chinese philosophy and science. This syncretic approach allows combining ideas that are oppositional. Due to the widespread use of the syncretic approach, each of the Chinese intellectual schools includes elements of other traditions. It is therefore extremely difficult to clearly distinguish the specific characteristics of each of the original schools of thought in China.

Thus, it makes sense to talk about the syncretic Chinese value tradition, and not about the philosophy of each particular school as distinct and well-defined. The sanjiao (literally "three teachings") or the Chinese synthesis of Confucianism, Taoism and Buddhism, based on doctrinal and ideological affinity. «In Schelling's Philosophie der Mythologie, however, religion does play the decisive role. For Schelling, the key to understanding why "the patriachical principle has maintained its influence and power for thousands of years" in China is the abrupt change of the religion of heaven into the deification of the state - "religio astralis in rempliblicam versa"». ${ }^{2}$

It is impossible to understand the cultural code of East Asia without taking into account all its origins, especially Buddhism. It is impossible to understand the Far Eastern society, without the idea of the illusiveness of the visible world, the reality of the unknowable absolute, the attitude towards empirical being (samsara) as suffering, and towards ideal being nirvana as bliss. Mahayana Buddhism, penetrated into East Asia, joined the local tradition. Growing together with local tradition, Buddhism formed a regional consciousness.

Buddhism - appeared in China in the first century. Chan Buddhism originated exactly in China. There was a sinicization of Mahayana Buddhism. The founder of Buddhism was the Buddha (Teacher). Fundamentals of the teaching of Buddhism: dukkha - the world is suffering; anity - earthly illusion; nirvana - absolute calm, the way of

\footnotetext{
${ }^{2}$ Roetz H. Confucian Ethics of the Axial Age: A Reconstruction under the Aspect of the Breakthrough Toward Postconventional Thinking. Albany: SUNY Press, 1993. P. 19.
} 
achieving nirvana is the middle path, through self-improvement; the purpose is to break the circle of samsara - the cycle of suffering, because of the removal of interest. Buddha first put a practical question: what should be done?

In his sermon Buddha called for the middle path, to avoid two extremes, routines and asceticism. Buddha offered a conscious way of dismissal. According to Gautama Buddha, salvation comes not from the outside, but from the middle of man. Buddhism denies the Atman - the substantive basis of the identity of the person, its reincarnation according to the laws of the universe (Buddhism denies the personality as something unchanged in time, but emphasizes the self-improvement of man).

The essence of Buddhist philosophy is in the theory of dharmas, which translates as quality, element, thing, law. Dharmas are instant elements that enter instant combinations. Being themselves unchanged, but combining each time in a new way, they form new structures. Dharmas are immaterial. The flow of dharm forms a personality. It depends on the combination of dharmas into which being a person is reborn. Karma (action) - the organizing force - arranges the elements in accordance with the actions of a person. Karma is a consequence of previous beings, and depends on it, since real life changes karma. The ultimate goal of Buddhism is salvation, deliverance from suffering, from attachment to samsara, entry into the state of super-existence. Nirvana repose, cessation of the excitement of dharmas, their new combinations: a person emerges from the cycle of being, but dharmas do not disappear, only their excitement stops. Nirvana is not death. Death is not a calming of dharmas, but an intermediate state before their new formation. According to the dharma teachings, the true reality of non-existence (nirvana) has no time, no forms, no divisions. In each dharma (moment of consciousness) there is present, past and future, time is recognized by Buddhism, but as a change of states of consciousness. The center of attention in Buddhism is transferred from the world of phenomena to the inner world of a person, while the external world is viewed primarily as a function of its mental processes, projecting the illusion of samsara in consciousness, and these processes themselves, in turn, act as reflections of meta-consciousness (nirvana). If at the level of samsara, space and time retain their relative meaning, then at the level of nirvana, space becomes its opposite, emptiness, and time - in the absence of time or eternity. 
The ideal of Buddhism is to eliminate the main contradiction between empirical being (samsara) and calm (nirvana), in achieving a state of identity. The path of self-improvement is the path of suppressing passions that cause suffering, the achievement of inner balance (it is for this purpose that arts such as the tea ceremony, martial arts and ikebana serve in East Asia). Suffering comes from ignorance (avidya). Ignorance exists at the level of samsara, to overcome which the thoughts of Buddhism are directed.

By stopping the wheel of being, one can enter nirvana. If the empirical and absolute inseparable, then the ultimate goal is available to everyone. The goal of Buddhism - deliverance from being - has determined its relation to being: the visible world is not true, not real. In Buddhism, the phenomenal world is subject to constant change and therefore unreal, illusory, it is maya, or the untrue world. Maya is a void, illusory world, as opposed to the undivided world that stands behind it and which, from the point of view of Buddhism, is the true reality.

From the point of view of Buddhism, the true world is non-existence, the Buddha called this world the world of nirvana, which knows no boundaries, knows no form. Really true-being. True-existence is attributefree, empty, in it, in an undetermined form, everything is already there. The original truth of Buddhism is the statement that life is suffering: birth is suffering, unfulfilled desire is suffering, and satisfied desire is suffering. The source of suffering is attachment of any kind. Non-existence or emptiness, where things are not dependent on each other, Buddhism considers the only reality. In reality, that which is permanent, indestructible, and indestructible that which does not arise, does not create, is the true, original nature of things.

The Buddhist way of getting rid of being is the eightfold way: the right look, the right attitude, the right speech, the right action, the right behavior, the right aspiration, the right memorization, the right concentration.

The first two phases of the eightfold path - the right view, the right attitude - are the immediate perception of the world. The fourth phase of the octal path, the «right action» - freedom, unconditioned, means nonviolation of the natural development of things. In the highest, eighth phase - «right concentration» - the non-duality of consciousness is reached - the state of one-being. This is enlightenment. Only through 
concentration is liberation possible. The less contact with empirical being (samsara), the more a person shrinks in his desires, the more he approaches nirvana. To reach the center of the twelve-fold circle of being is possible only by overcoming all twelve types of attachments to samsara. The eightfold path is the deliverance from suffering, having passed which a person achieves liberation.

Confucianism and Taoism do not diverge in this main issue of attaining deliverance with Buddhism: enlightenment can be achieved only through the efforts of one's own spirit. Everyone goes to liberation in his own way. To follow one's nature, to be oneself - this is Tao (way) asserts Taoism. And Confucianism believes that the ideal person is impossible without ethics: humanity, duty-justice), sensitivity and mind-knowledge.

Equally important in the understanding of the culture of the East Asian region is the philosophy of Yinyang (yin-yang). This is the oldest ancient philosophical schools in ancient China specializing in ontological issues. An important aspect of the yin-yang philosophy was astronomy and astrology. The yin-yang school emphasized the correlation of human activity with the positions of the sun, the moon and the stars. Within the yin-yang school, natural phenomena were studied, including weather, clouds, fog and winds. Astronomical and astrological observation was an important part of Chinese practical philosophy, since it was used to determine the favorable times for a wide range of social, cultural and political actions.

Yin-Yang represents systematic cosmology, which is based on the correlation and analogy between man, state and space. Correspondence (correlation) between social and natural phenomena (such as natural disasters, astronomical and meteorological phenomena) was one of the basic principles of the yin-yang philosophy.

The notion of conformity is closely linked to the idea of the middle, which is considered differently in Chinese philosophy: conformity, cooperation, integration, stability and equilibrium. The middle - it means not to deviate in any direction. Constancy means immutability. The middle ground is the achievement of the equilibrium of the beginnings. Hence - the understanding of the middle as a moving equilibrium, equilibrium, a mobile type of communication that forms the whole. The middle, linking all things, keeps the world in equilibrium. Due to the law of the middle there is order in the universe, alternating day and night, four 
seasons. The middle was understood as a supreme ideal. The middle produces harmony.

According to the ideas of East Asian culture, the whole world is based on the principle of the middle - nature, man, society, art and state. "Yet, the prephilosophical age also knows a cosmological, sacral geography in which the world is divided into regions of increasing ontological importance with the royal domain as their center»». ${ }^{3}$

The meaning of the middle category is very important in the Chinese philosophical, ethical and aesthetic concept; it is understood not only as a certain state of consistency, but also of its own cosmological significance, existing in its own right, rising in line with such concepts as Tao and Li. The basis of true art is the ability to find and feel the middle. Action must control the middle, and then the result will be the consistency of the external and inner worlds. The whole thing is in the middle, and accordingly, the world rhythm. The main thing, when all the elements are balanced, are in a state of moving equilibrium. Taoism, Buddhism and Confucianism proclaimed the law of the middle path.

The main principle of this school was the change in the circle everything is in constant change, but the change itself is on an unchanging path. Constancy - in a constant rotation in a circle, in a series of darkness (yin) and light (yang). Light darkness, yin-yang are inseparable, interpenetrating. By constantly changing themselves, they lead to the change of one situation by another, interconnecting each other.

Interaction of yin-yang generates five elements: in the center - the earth, around - water, fire, tree, metal. Thanks to the yin-yang and the five elements all things are born. The twofold nature of the absolute, the interpenetrability and complementarity of centrifugal yin and centripetal yang (yin as it were enveloping yang) form an introvert model. Yin-yang are inseparable, closed within the same circle in the form of curved halves, ready to move one to the other.

The law of the world rhythm leads to the change of one situation by another, spreading the path to world development (according to the principle of moving back and forth, decreasing-increase, tide-tide). Constancy - in the law of the middle, holding the world in equilibrium. The visible world is a process, the world of the invisible is peace; real is not a phenomenal world (that which is, will surely disappear), but a

\footnotetext{
${ }^{3}$ Roetz H. Confucian Ethics of the Axial Age: A Reconstruction under the Aspect of the Breakthrough Toward Postconventional Thinking. Albany: SUNY Press, 1993. P. 40.
} 
strictly conditioned process of alternating situations. The real coordinate system, which captures the path of world development, is the law of change, conditioned by the yin-yang cycle (yin is peace, yang is a movement). Everything moves on the principle of back and forth, descending-growth. Everything meets the natural rhythm. The sun is coming, the moon is rising. The moon is coming, the sun is rising. By opening the law of change, the principle of the alternation of things, the universal states of the world, one can foresee the impending situation. In fact, things speak little about what, but if you open the system of their changes, then you can foresee what will happen to them at the next moment. In the yin-yang school, the sky was the highest archetype. The sky created images that were realized on the earth. So there were changes.

Cosmos (the sun, moon, stars) creates images, and on the ground, the landscape, flora and fauna (mountains, rivers, animals and plants) acquire forms - and everything is in constant circulation. Presenting in all, yinyang act in each other, which creates an internal source of motion. There is no need for the firsthand, the first motor, in external opposition: the Tao follows to himself. Universal development is the result of the yin-yang interlacing.

The yin-yang school developed a concept of space consisting of $q i$ (the energy that forms and organizes matter and causes change), the interaction of yin and yang and the five elements. Yin-yang, the five stages and the concept of qi eventually united to provide the basis for a new theory of correspondence between heaven and earth, on the one hand, and the political sphere, on the other. «Indeed, the Chinese assumed a fully monistic cosmos: "Man and nature did not form two separate reals, but one unique society"»».

From the point of view of the yin-yang school, space is due to the circulation of qi, circulation is due to the interaction of yin-yang. The ability to circulate is immanent qi, due to the twin nature of Yin-yang, to bring them in motion wasnot needed external force. Not only the character of a person, but also the nature of the season depends on the circulation of qi. Human health depends on the extent to which it is endowed with qi and whether it circulates correctly. You can accumulate qi, you can lose it. Complete loss of qi leads to death. Things with the same qi are attracted to each other. Qi can form the basis of both good and bad.

${ }^{4}$ Puett M. J. To Become a God: Cosmology, Sacrifice, and Self - Divinization in Early China. Cambridge: Harvard University Press, 2002. P. 8. 
The practice of the yin-yang school is understood as a process that is powerful in its cosmic influence. Social and artistic practices (calligraphy, Wushu) are formulated in accordance with the energy circulation - yin and yang. The cosmological, epistemological and ethical meaning of the concept of qi is revealed in philosophical writings, anthropological - in works of medicine, martial arts, geomancer, aesthetic - in treatises on calligraphy, painting and poetry. There is no area of Chinese culture where the category of qi would not play a key role. Interpretation qi is the central problem of sinology since its inception up to the present time inclusive. Chaos and order are two faces of energy-qi. Yin yang two modes qi (pneuma).

In the process of cosmogenesis, qi is polarized on yin and yang. Qi is a material energy substance. Qi, being in a constant motion, forms things, causing change. Qi is a material power, energy, as well as vitality and in this capacity, takes part in the process of the formation of things and people. In Chinese philosophy, li and qi (principle (form) and matter (content)) acted as two aspects related to each other.

The yin-yang philosophy is the result of observing the phenomena of nature (the change of the night-day, cold-heat, rest-movement), the result of which was the idea of the two-united nature of the absolute, the two-united nature of things, or the non-dual model of the world. The idea of the perfect absolute, introverted yin-yang, has become a structuring beginning, which manifests itself literally in any aspect of East Asian culture.

In fact, the yin-yang cosmology emphasized the correlation between heaven, earth and man as components of a single cosmic order. «For China, he argued, the dominant tendency was "to associate the transcendent with the notion of an immanent cosmic and social order. Transcendence, then, occurred in China even within its immanentist cosmology» 5 . The central idea of the school is the universal unity of yin and yang, which is the basis of all ontology, cosmology and science of China, the Far East and South-East Asia.

Taoism, which experienced the influence of the yin-yang school, also recognized the development, the return to nothingness. The emptiness is deprived of form, but all throws in itself. Emptiness - the condition of the existence of things, allows them to find their nature. Nothing disappears, but only returns to nothingness, in order to reappear at the appropriate

${ }^{5}$ Puett M. J. To Become a God: Cosmology, Sacrifice, and Self - Divinization in Early China. Cambridge: Harvard University Press, 2002. P. 12. 
moment. Non-being has no form, being has a form. Nothingness emptiness - is the world of peace, being is the world of motion. What tells the whole movement is Tao. Tao is driving himself. Tao general, cosmic law, and the path of each being separately. Everyone has his own Tao.

The whole phenomenal world, which is not a real Tao, is its manifestation. Non-being and being pass each other, obeying the two-way movement back and forth, but between non-being and being there is no essential difference, being is only a temporary manifestation of nothingness. This determined the type of connection between what is not shaped and the shape. Higher being, or nothingness, emptiness, Tao, without form, has no plurality, no divisions, even in the form of higher initial forms or ideas as special immutable entities, independent of things, but are their prototype. Time, like space, is a Tao attribute, can't be measured.

Confucianism made the Tao a moral one. It specifies Tao in li: son's respect and brotherly love, loyalty and reciprocity, humanity, knowledge and courage, dignity, caution, justice, correct movements of the body, face expression and language. Representatives of the military thought school (Bing -Fa) also put the concept of Tao into the foundation of their theory. In Sun Tzu, it is defined as the first of five principles of military art (along with the conditions of heaven and earth, the qualities of the commander), which consists in the unity of the willful

thoughts of the people and the upper classes. Since the war in the treatise is regarded as a path (Tao) of deceit, the Tao connects it with the idea of a trick that was developed in late Taoism. «In Chinese, the phrase military strategy consists of two parts: Bing (meaning 'soldier') and Fa (meaning 'doctrine'), which together can also be translated to mean 'the art of war'. The golden era in the development of classical Chinese military strategy was the few hundred years between the beginning of the SpringAutumn period and the end of the Warring States period in Chinese history (772-221)».6

The idea of spontaneous development, defining in Taoism, led to a special model of behavior, the principle of non-intervention, non-violence over the nature of things that is called non-action. The idea is that we must stop trying to force the action. Our actions should be natural, then the desired results are achieved.

${ }^{6}$ Chen Min. Asian Management Systems: Chinese, Japanese and Korean Styles of Business. London : Thomson Learning, 2004. P. 33. 
The principle of non-action is a natural consequence of the reality of non-existence. Spontaneity was understood as following one's nature. Following your nature, you follow Tao. To follow the Tao, it does not require any violence over your nature; you only need to trust it. To follow wu wei means to feel the rhythm of the cosmos. To control non-action is to understand the nature of what is happening, not to resort to violence. Inaction is the use of natural properties. This is a model of behavior, based on the principle of non-violation of the natural order of things, to act by non-action. To act is to disrupt the harmony of the universe. Everything is already in potency, and you need not to act, but to guess, to penetrate into what you already have by the power of intuition, and you just need to find the appropriate moment to reveal it. In addition, Taoism sought - to reveal its own nature. Thus, wu wei is an action consistent with the laws of nature, commensurability with the natural rhythm, with constantly changing conditions.

To catch the rhythm of the universe, to get into the thing, to live with it in unison. A person who did not want to violate the rhythm of world development had to change in accordance with it.

Taoism recommends cultivating inaction, watching the natural world. Created in the war, the Taoist concept in the wu wei argues that action must merge in harmony with the forces that rule, go with the flow, in contrast to the Confucian concept to do the right thing. The wu wei is an important element of the art of war. The tradition in the wu wei is a conscious opportunism, activity taking into account the needs of place and time. The philosophy of Taoism puts the problem of the natural in the center of its reflections, that is, to live in harmony with the circumstances. The mind that seeks general patterns and builds calculations, Taoism contrasts the coincidence. The Chinese tradition in the wu wei contrasts with the Western heroism.

The wu wei principle is connected with the idea of a non-causal connection, according to which the world is a huge organism, a spontaneously developing continuum, where everything is correlatively connected with each other in accordance with the yin-yang model. Everything cooperates in mutual service, moreover, each thing, having relative freedom, plays its role, depending on the position in the system. Everything in nature is so interconnected that the slightest fluctuation does not pass without a trace. 
Taoism has questioned the standardization and unanimity of events and processes in society. The Taoist approach emphasized the spontaneity of phenomena; the nature of society contradicts any attempts to classify, control and manipulate. Taoism was divided into philosophical and religious - faith in spirits and worship of local deities. The symbol of Taoism - water, other symbols of a dry tree - a state of meditation, which simultaneously provides a shadow for the traveler, butterfly - a symbol of metamorphosis. Taoism complemented the yin-yang principle of the Tao principle. The cosmos appears to be an appropriate, Taoist, Taoist-driven, Taoist principle that is natural expediency. When a person does not prefer a certain temptation, he is able to control his behavior, adapt to any situation, that is to go to the path of Tao. Unlike Confucianism, Taoism argues that both people and the state should be guided not by artificial, ethical norms and rules, but by the laws of nature. The only way of life is to adhere to the Tao's natural law. In a practical plane Taoism embodied in alchemy, self-defense schools, which acted on the basis of the idea of the vey - to act without acting. "Civilizations of Asia did not, for specific socio-political historical reasons, generate the conditions to sustain either the city as we commonly understand it today or the modern university. In other critical respects, however, China was ripe for a cognate revolution in ontological frames: the absence of slave labour caused less suspicion of the utility of inventions; Taoist precepts regarding Nature, whilst antinomothetic in form, assisted in the development of medical, alchemical and physical sciences; and the achievement of a high degree of ethical rationalism, as Weber had already alluded to, was historically surpassed only by the irrationalism of Protestant sects which later proved fateful for both the New World and Europe.»>

One can't ignore and Confucianism with its idealization of the past. The immediate cause that Confucius prompted to turn to the past was dissatisfaction with his contemporary orders. Confucius's call for the revival of ancient times was based on its negative attitude to reality, to the principles of state administration. This explains the idealization of the oldest society, which in its image was a golden age, and its rulers are wise rulers guided by the principles of justice, virtue, loyalty and humanity. Indeed, the picture of general welfare, represented by Confucius, can't but

${ }^{7}$ Mandalios J. Civilizational Complexes and Processes: Elias, Nelson and Eisenstadt. In Handbook of historical sociology / ed. by Gerard Delanty and Engin F. Isin. London; Thousand Oaks, Calif.: SAGE, 2003. P. 74. 
call the relation to the past as an ideal. To restore the past, to help the human memory to hold the found - not less creative moment of development than the search for a new one. New is existing thanks to the old, grows out of it. By returning to the original, man reaches the integrity, unity with the world. This is the essence of Confucian traditionalism.

With the notion of traditionalism, the observance of the normative passed inextricably linked ethics of Confucianism. Recognizing the ineffectiveness and obsolete practice of legalism, Confucius proclaimed that not the law should be the basis of society and state, but a ritual based on normative tradition. "The long-term result was the loss of dignity of Heaven, the growing emphasis on its dysteleogical natural side, and a "humanistic" turn in thinking». ${ }^{8}$

As we see, Confucianism puts forward its special ethics - the ethics of a thoroughly ritualized life. The achievement of this ethical ideal requires unceasing moral endeavor. Such an ethical will was not a temporary emotional impulse or the result of a spontaneous decision, but a constant discipline that did not depend on sentiments, feelings and external circumstances. Confucius likened to the noble man of cypress, endowed with this discipline, that does not dump his green suit even in the cold. Achieved by training and self-improvement the internal state of an ethically perfect personality arises in the process of strict self-restraint. These were heroes of moral behavior who did not make any movement, did not say a single word that was not consistent with the proper rules of conduct. "And in a time when the old order declines, Confucians established a new, unmythical center of the world: the junzi, the "gentleman", whose very presence, wherever he might be, is an assurance of the existence of morality and culture». ${ }^{9}$

According to Confucius, a wise ruler should take care of the correction of names. The latter implies the moral verdict of judgments and deeds. The most important thing in politics is correct, relevant, proper and accurate use of words. Confucius formulated the concept of correction of names, so that inappropriate words did not make a mess in the affairs of the state. For Confucius the word is one of the Tao attributes; you must keep it clean so as not to break the path. The word is the organizing

\footnotetext{
${ }^{8}$ Roetz H. Confucian Ethics of the Axial Age: A Reconstruction under the Aspect of the Breakthrough Toward Postconventional Thinking. Albany: SUNY Press, 1993. 373 p. 39.

${ }^{9}$ Ibid.
} 
moment of the general order. The word in the system of Confucian consciousness had the same measure of reality, as the objective world, as well as things that correspond to general concepts, thus, the concrete and abstract is not delimited.

Historically, the emergence of Confucianism can be regarded as a process of rationalization of archaic religion and social structure in the categories of morality and administrative control. In general, in the Chinese classical philosophy, the Confucianism -Legalism distinction can be traced based on the orientation towards ethical and ritual decency (le) or on the legal law (fa), «... interschool polemics of the late Warring States, is presented in the guise of a debate between "law" (fa) and "ritual" (li)». ${ }^{10}$

The Confucian priority of decency as an ethical norm and the proper management of people with the help of lee stems from the idea of the primordial good nature of man, and the opposite position of the Legalism who gave priority to the law and the proper management of people through punishments and rewards is due to the idea of the primordial evil nature of man. In this case, the management of people is derived from human nature. The essence of Confucianism in its ethics and humanism. The fact is that, giving preference to ethics, Confucianism chose a nonviolent social order, based on a set of rules of proper conduct (li).

In Confucianism, the concept played the role of the basic ethical principle governing relations between people in different spheres of life, norms of their behavior. Is the system of norms of behavior, the embodiment of the correct way from the point of view of Confucianism. "When Confucianism subordinates politics to morality, it overtakes the legacy of the belief in Heaven». ${ }^{11}$

The notion of the influence of moral qualities on the phenomena of nature - one of the main in Confucianism. The order of a person depends on the behavior of a person in space: the correct change of seasons; the correct alternation of yin-yang, from which, in turn, the correct ratio of the five elements depends. From the correct ratio of the latter depend on a well-ordered life, the correct relationship between people, and on the behavior of people depends on the correct ratio of elements, that is, the entire world order. In Confucianism, the world does not divide into human

\footnotetext{
${ }^{10}$ Roetz H. Confucian Ethics of the Axial Age: A Reconstruction under the Aspect of the Breakthrough Toward Postconventional Thinking. Albany: SUNY Press, 1993. P. 39.

${ }^{11}$ Ibid.
} 
and natural, physical and psychic, but perceived as an organic whole as integrity. One can say that Confucianism loves the ritual and the scientist, placing them at the center of the historical process. «This is no accident, since the fundamental structural characteristics of civilizing processes were obviously present in an imperially immured China: the monopolistic means of control of social and economic life by a scholarly officialdom ('the mandarins') who relatively early secured (a) the pacification of feudal warrior-dominated spaces and (b) the 'means of orientation', that is, knowledge production, acquisition and dissemination.»" ${ }^{12}$

The basic principles of Confucianism were: ritual; humanity; honoring ancestors; education. Confucianism, as the official ideology of China lasted until 1911. If the Taoist philosophy is cosmological, then the Confucian moral. The fact of the primacy of Confucianism among the other Chinese philosophical schools is due to the historical evolution of concrete, material magic and mantic through ontology and cosmology to ethics and abstract universal moral imperative. "It further involved a struggle of "rationality" over myth and an "ethical rebellion" against "the unreal figures of the gods"». ${ }^{13}$

The transition from cosmological antithesis to chaos-space, to the universal ethics of good and evil. Therefore, the transformation of an ontological-unmatched Tao into an ethical li caused a certain spiritual upheaval in the Chinese system of values, «... the movement from mythos to logos or 'from religion to philosophy,' or from analogical to causal thinking ...» ${ }^{14}$. A feature of Buddhism, Taoism and Confucianism, is that they are simultaneously religions, sciences, philosophies and the main ethics.

\section{CONCLUSIONS}

Chinese civilization and its philosophical and ethical concepts have formed the fundamental cultural and spiritual values of the entire East Asian region. The Chinese philosophical and ethical tradition lies at the basis of family relations, education, socio-economic and ideological and political structures of East Asian societies. The complex of transcendental

\footnotetext{
${ }^{12}$ Mandalios J. Civilizational Complexes and Processes: Elias, Nelson and Eisenstadt. In Handbook of historical sociology / ed. by Gerard Delanty and Engin F. Isin. London; Thousand Oaks, Calif.: SAGE, 2003. P. 69.

3 Puett M. J. To Become a God: Cosmology, Sacrifice, and Self-Divinization in Early China. Cambridge: Harvard University Press, 2002. P. 11.

${ }^{14}$ Ibid. P. 18.
} 
values developed by Chinese civilization is the value axis of the formation of the socio-cultural context of the Far East. This value complex is decisive in the historical processes taking place in modern East Asian societies. Despite the presence of national characteristics of the countries of the Far East and the fact that in each country the influence of Chinese civilization superimposed on a certain cultural and ethnic base, Confucianism was the skeleton on which the culture and history of the East Asian region is based. Indeed, in the dialectic of the single-specificthe general-specific, the national is a manifestation of the common, the universal. The general is the essence of the concrete. By discovering common features in cultures, we comprehend the meanings of cultures.

The notion of the introversion of Yin-Yang served as a formative principle that determined the structure of the thinking of the Far Eastern peoples, superimposed on any type of human activity, starting from an understanding of the real and ending with an understanding of the due. The dual (or non-dual) model of the world implies the inseparability of physical and moral laws.

The interaction of the interpenetrating forces of the yin-yang - led to the second feature of East Asian cultures - focusing on the inner as a source of self-development of the thing. If the universal movement is understood as the transition of yin to yang, then with concentration on the inner, on the center of the monocentric model, development occurs cyclically. Yin-Yang, gradually diminishing, gradually growing in each other, mutually alternate, which creates movement in a circle. The world develops in cycles in a monocentric pattern, by moving back and forth, increasing and decreasing. The center is at rest - the absolute, from it concentric circles diverge being. One era passes under the yin sign, the other under the yang sign. The focus on the inner and cyclical permeates all aspects of East Asian culture. If time is cyclical and the past repeats, then future time is nothing but a renewing present and past. All three times are located as if in the same plane. Consciousness, oriented to the laws of nature, to the idea of cycling, where everything comes up from nothingness and returns to non-existence. The universe has no beginning, no end, one year ends, another begins.

True reality is non-existence, the absence of forms, but where everything is already there and occasionally floats into the phenomenal world. Thus, the difference between non-being and being in this system of 
thinking comes down to the fact that one has a form, a visible appearance, the other has not, but there is no gap between non-being and being, they constantly go into each other. Tao personifies the unity of being and nonbeing. Hence the relativity of all oppositions: life and death, good and evil, movement and peace. Non-existence, not something otherworldly, not a mystery, terrifying, a sign of imminent death, disappearance, but the potency of life. Not without reason, Tai Chi (absolute) is depicted as a circle, two curved halves of which, light - yang and dark - yin, are ready to go one into the other.

The world is a non-stop process of becoming, and ideas about it must constantly change. Associated with this is the peculiarity of oriental terms, their ambiguity, situationality - dependence on place and time. They are mobile, for they reflect the process, they are situational, for they bear the color of that state or the person to which they relate. The essence is inseparable from the phenomenon, the subject from the object, the idea from the image. Hence its artistic form.

The world spontaneously develops from itself, and therefore the source of its self-development, non-being, from which everything grows, takes on major importance. But if nothing is the root, the source of being, then complete, absolute disappearance, like the emergence of something fundamentally new, is impossible. In nonexistence, everything is already there, and man is only called upon to imitate and reveal what is. If the basis of Western civilization is the idea of being, then the basis of Eastern is the idea of non-existence. Without awareness of this postulate, it is impossible to understand any category of East Asian culture.

The feeling of non-being time. If consciousness placed an emphasis on the fluidity, the elusiveness of things, then there could not be a fixed time linear to its perception. The goal is to free a person from the sensation of space and time, which allows you to soar above being, to penetrate into the invisible. Hence the timelessness of the East Asian world perception. This timelessness conveys the natural rhythm of nature. The constant cycle of the four seasons is one of the main organizing principles of East Asian culture. Historical dates are not mentioned in art and literature, there is a season - spring, summer, autumn, winter. In the Eastern tradition, the recognition of two-way traffic gave rise to the idea of the reversible nature of time. The idea of non-being disposed to nonexistent perception of time. Such an attitude towards non-existence gave 
rise to the tendency of time to move backwards: the vector of time is directed to the past even when it comes to the future.

According to $M$. Weber, the gap between «worldly» and «otherworldly» caused in Western civilization a sense of dissatisfaction with the existing order on earth and pushed it towards social changes. Eastern tradition is alien to active austerity in the world. The Far Eastern teachings considered the order existing in nature as the only correct one. Hence the principle of non-doing, not re-making the world.

Far Eastern consciousness turned to the past. Such a mentality could not but affect the historical path of nations. A special attitude to the past as a pledge of the future has created a desire not to overcome, but to preserve what is in the past. This led to traditionalism - not to replace, but to preserve what was once found. The ideal of East Asian culture is not directed to the future and is not so much connected with creativity, as it has a strong tendency to appeal to ancestors, to the great heroes of the past. Looking for ideals and models in the past is a kind of specificity of Eastern thinking. For a long time, following ancient patterns was legalized, it was a sign of authentic taste and education. The notion of cyclicality was one of the origins of traditionalism.

\section{SUMMARY}

The article discusses the philosophical and ethical aspect of the formative influence of Chinese civilization on the cultures of the East Asian region. The author emphasizes that the philosophical and scientific thought of East Asian states developed in line with the basic ethical-value systems of Chinese civilization, such as Taoism, Confucianism, the YinYang School and Buddhism. East Asian cultures form the sociocultural macrosystem of the Far Eastern type of civilizations. In the middle of this macrotype there are certain cultural differences. The peculiarity of each culture is manifested through the system of customs, ideas and practices characteristic of it. However, all East-Asian cultures have one basis - the Chinese value tradition. This article is an attempt to identify the transcendental content of East Asian cultures.

\section{REFERENCES}

1. Chen Min. Asian Management Systems: Chinese, Japanese and Korean Styles of Business. London : Thomson Learning, 2004. 278 p. 
2. Lewis M. E. Writing and Authority in Early China, Albany: State University of New York Press, 1999. 544 p.

3. Mandalios J. Civilizational Complexes and Processes: Elias, Nelson and Eisenstadt. In Handbook of historical sociology / ed. by Gerard Delanty and Engin F. Isin. London; Thousand Oaks, Calif.: SAGE, 2003. $417 \mathrm{p}$.

4. Puett M. J. To Become a God: Cosmology, Sacrifice, and Self Divinization in Early China. Cambridge: Harvard University Press, 2002. $358 \mathrm{p}$.

5. Roetz H. Confucian Ethics of the Axial Age: A Reconstruction under the Aspect of the Breakthrough Toward Postconventional Thinking. Albany: SUNY Press, 1993.373 p.

\section{Information about the author:}

Kudrya I. G.

Doctor of Philosophy, Associate professor of V. I. Vernadsky Tavria national University Educational and Scientific Humanitarian Institute's Chair of History 33, I. Kudri str., City of Kyiv, Ukraine 